\title{
A HERANÇA MARIOANDRADIANA: FONTE DE INSPIRAÇÃO PARA PESQUISAS DECOLONIZADORAS
}

MARIOANDRADIANA HERITAGE: SOURCE OF INSPIRATION FOR DECOLONIZING RESEARCH

https://orcid.org/0000-0003-4471-4665 Roberta Cristina de Paula ${ }^{\mathrm{A}}$

A Prefeitura Municipal de Campinas (PMC), Campinas, SP, Brasil

Recebido em: 14 dez. 2021 | Aceito em: 2 fev. 2022

Correspondência: Roberta (rodepaula@hotmail.com)

\section{Resumo}

Este artigo apresenta os entrelaçamentos entre os meus trabalhos de conclusão de Curso, respectivamente a Graduação, o Mestrado e Doutorado em Educação (PAULA 2003; 2012; 2019), com o objetivo de pensar a Pedagogia da Infância para além dos espaços educacionais formais. Destaco que uma das premissas dos desdobramentos destes estudos foi a obra da pesquisadora Ana Lúcia Goulart de Faria (2002), sobre os Parques Infantis da capital paulista de 1935 a 1938, proposta essa implementada por Mário de Andrade, então diretor do Departamento de Cultura de São Paulo. Os três trabalhos por mim elaborados são de caráter qualitativo, sendo que as metodologias empregadas foram pesquisa histórica, bibliográfica e uma etnografia. As investigações tiveram como principais campos teóricos a Pedagogia, os Estudos Sociais da Infância, e a Antropologia. Como ponto de convergência, os dados produzidos mostram que a linguagem corporal é uma das mais importantes formas de expressão, e que as manifestações das culturas populares, como a dança, a música e o canto são potencializadores dessa linguagem.

Palavras-chave: Educação; Infâncias; Parque infantil; Escola de Samba; Danças.

\begin{abstract}
This article presents the interwining between my course conclusion works, respectievely the Undergraduate, Masters and Doctorate in Education (PAULA 2003; 2012; 2019), with the objective of thinking the Pedagogy of Childhood beyond the formal educational spaces. This highlihts that one of the premises of the unfolding of these studies was the work of researcher Ana Lúcia Goulart de Faria (2002), about the Children's Parks in São Paulo from 1935 to 1938, this proposal was implemented by Mário de Andrade, then director of the São Paulo Department of Culture. The three works developed by me are of a qualitative nature, and the methologies used were historical and ethnography research. The investigations had as main theorical fields Pedagogy Social Studies of Childhood, and Anthropology. As a point of convergence, the data produced show that body language is one of the most important forms of expression, and that the manifestations of popular cultures, such as dance, music and singing, are potentiators of this language.
\end{abstract}

Keywords: Education; Childhoods; Playground; Samba school; Dances. 


\section{Introdução}

\section{$\hat{E} h$, Barra Funda, onde a arte \\ Do menino floresceu \\ Entre notas musicais, poemas, saraus \\ O movimento modernista aconteceu. Dennis Patolino, Guilherme Garoa, Victor $7^{i}$}

Inicio registrando minha alegria em escrever um trabalho que poderá compor este Dossiê, me fazendo rememorar trajetórias, pensar como fui me encontrando com a obra de Mário de Andrade (MA), ou ainda, quais outras obras me levaram às suas produções.

Conforme referenciei em Paula (2012), como Mikhail Bakhtin (1999) identificou em Rabelais o corifeu, por ele apontar outras perspectivas para a cultura popular da Idade Média, considero que Mário de Andrade, esse intelectual modernista é um corifeu dos nossos tempos, uma vez que seus estudos, também nos possibilita a construção de novos olhares e de diferentes diálogos com o campo das culturas populares brasileiras.

Ao entrelaçar as minhas trajetórias pessoal e acadêmica tenho realizado pesquisas na área da educação de modo a provocar o pensamento pedagógico que historicamente hegemônico, não considerando as crianças como protagonistas no processo, priorizando a linguagem escrita em detrimento de tantas outras, invisibilizando a diversidade das culturas populares brasileiras, com isso perpetuando o ideário colonizador eurocêntrico-estadunidense. No artigo Formação continuada e Pedagogia Decolonial: o M.A.R ${ }^{\mathrm{ii}}$ e o Samba, corroboro as palavras das autoras que afirmam:

Para o pensamento decolonial é preciso pensar e agir sob crítica ao hegemônico, mas sobretudo por um modo "outro", que conteste saberes historicamente eurocentrados. E mais que "dar voz" aos oprimidos, mas promover sistemas de afirmação de lugar, fala, e igualmente, escuta. É preconizar histórias contadas por lugares, vozes e sujeitos que o hegemônico tratou de apagar. (dos SANTOS NASCIMENTO; SOUZA, 2020, p.47)

Dialogando com esse contexto, Fernanda Leme (2008) descreve Mario de Andrade (MA) como:

O poeta [que] tinha, em sua trajetória, um respeito pelos distintos grupos produtores e fruidores de cultura, reconhecendo que os menos favorecidos, aí incluídos os negros, os índios, a classe operária, as mulheres e as crianças tinham sua cultura negada, ansiava por garantir no que ele chamava de cultura nacional, um espaço para essas culturas negadas e silenciadas. (LEME, 2008, p.64) 
O interesse em aprofundar-me no campo das culturas populares, particularmente as danças, se deu primeiramente de forma exploratória, com minha participação no Grupo de Danças Populares Urucungos, Puítas e Quijengues, de Campinas - SP, fundado pela mulher, negra, professora e militante do Movimento Negro, Raquel Trindade, e mais tarde academicamente; enfatizo que as pesquisas (PAULA 2003, 2012; 2019) respectivamente, um trabalho de conclusão de curso (TCC), a investigação de mestrado e doutorado, são perpassadas pelas temáticas da educação, infâncias, linguagem corporal, e expressões das culturas populares.

Foi no início da graduação em Pedagogia, cursado na Faculdade de Educação da Universidade Estadual de Campinas (FE-UNICAMP) que conheci a professora Ana Lúcia Goulart de Faria, através de sua pesquisa inteirei-me de outras facetas do, até então, para mim, escritor MA. A tese de doutoramento da pesquisadora foi publicada no livro Educação Préescolar e Cultura: para uma Pedagogia da Educação Infantil (FARIA, 2002), apresenta os Parques Infantis (PI) de São Paulo sob a gestão de Andrade, então diretor do Departamento de Cultura daquele município (DCSP). O estudo apresenta esses estabelecimentos públicos de educação e cuidado que asseguravam o espaço-tempo para o brincar, enfatizando a proposta pedagógica que, entre outros aspectos, incluía experiências a partir de elementos das culturas populares como a dança e música, privilegiando as dimensões lúdica e artística, reconhecendo as crianças como consumidoras e produtoras de culturas.

Entende-se que a investigação realizada por Faria (2002) considera que a experiência fomentada por MA é uma referência tanto para a construção de uma Pedagogia da Educação Infantil, que rompa com o modelo escolarizado que antecipa a alfabetização das crianças pequenas, como para a Educação das Infâncias, e para a formação de profissionais docentes e gestores/as que atuam em diferentes contextos educacionais. Afirmo isso pelo fato de que o projeto implementado fundamentava-se na cultura, isto é, articulava o binômio educaçãocultura.

Fernanda Leme (2008) conta que Paulo Duarte, um dos colaboradores do DCSP, dizia que MA tinha um pensamento que buscava a brasilidade, porém: “... não podemos reduzir a busca pela brasilidade a este projeto, pois o movimento não é exclusivamente de Mário de Andrade, mas marca do grupo ao qual ele pertencia, conhecido como Movimento Modernista" (LEME, 2008, p.59). Faria (2002) diz que essa iniciativa dos PI compunha um projeto de política cultural do município, na gestão do prefeito Fábio Prado (1934-1938), demonstrando a abrangência de uma política pública. 
Nesse cenário, Faria (2002) aponta outra característica desse homem público: o educador. Ao ser "apresentada" ao Mário, educador, que sendo um visionário, já vislumbrava nos anos de 1930, a potência inerente às expressões das culturas populares, fui instigada a aprofundar os conhecimentos nesse campo, uma maneira de me apropriar de outros elementos que colaborassem com a minha atuação na área educacional, associando educação, arte e culturas.

Proponho-me no presente trabalho apresentar as três pesquisas realizadas a partir do marcador educação-cultura. Mesmo que provenientes de diferentes contextos e relações, os estudos privilegiaram "beber" em fontes que podem inspirar tantos outros espaços educacionais, desde a creche, a pré-escola, escola, quiçá provoquem a construção de pedagogias subversivas, emancipatórias e revolucionárias, assim como tem sido as inspirações marioandradianas e farianas, advindas das pesquisas do múltiplo Mário de Andrade e da professora, militante, socialista, feminista, criancista e provocadora Ana Lúcia Goulart de Faria, especificamente para a área da Pedagogia da Educação Infantil e para a Educação das Infâncias.

Faz-se necessário registrar que, mesmo sendo as pesquisas processos que exigem períodos de intensa dedicação, o que acaba por imprimir um caráter solitário, como bem coloca Faria (2002) sobre a elaboração de uma tese. Ressalto que esses estudos exemplificam o resultado de uma construção coletiva que se deu também com a minha participação no Grupo de Estudos e Pesquisa em Educação e Diferenciação Sócio-Cultural (GEPEDISC-Culturas Infantis) da FE-UNICAMP, coordenado pela professora Ana L. G. de Faria, grupo esse que se caracteriza por experiências que objetivam relações horizontais, de solidariedade e cooperação, a construção de saberes no coletivo, o estranhamento do familiar e o familiarizar-se com o estranho, o convívio com as diferenças e o aprendizado entre pares. Saliento que uma das bases para nossas produções acadêmicas são as leituras dos diversos trabalhos realizados por integrantes do GEPEDISC, entre eles TCCs, dissertações, teses, artigos, resumos e trabalhos completos em congressos, que entre outros aspectos, evidenciam as relações de gênero, étnicas, e diversidade sócio-cultural ${ }^{\mathrm{iii}}$.

Durante todos os processos em questão, acompanhei debates, compartilhei reflexões, recebi sugestões de leituras feitas por colegas de grupo, os quais proporcionaram com que os trabalhos agregassem contribuições valorosas, referendando um marcador desse coletivo que são as produções que se baseiam na colaboração, referendando uma prática decolonizadora no sentido que contraria a competitividade tão marcante em uma sociedade capitalista, a qual prioriza o individualismo em detrimento do senso de coletividade. 


\title{
“Os Pequenininhos do Parque"
}

\author{
Buscar os registros deixados nos corpos é uma das \\ mais interessantes formas de tecer interpretações a \\ respeito do passado e, assim alargar a compreensão \\ do presente. Ele é um documento vivo em que a idéia \\ de tempo é forjada em sua materialidade por atos de \\ conhecimento. \\ SOARES; FRAGA, 2003, p.86
}

Ao final do curso de Pedagogia desenvolvi o TCC intitulado "Os Pequenininhos do Parque" A linguagem corporal das crianças pequenas de um Parque Infantil de Campinas (1942-1952), tendo como eixo central problematizar a representação da linguagem corporal, com base em fontes documentais, das crianças pequenas, de 3 a 6 anos, frequentadoras do Parque Infantil da Vila Industrial, em Campinas, SP, em seus dez primeiros anos de funcionamento.

A investigação, de caráter qualitativo, deu-se através de uma pesquisa histórica, e os procedimentos metodológicos incluíram idas à unidade educacional para levantamento e seleção dos documentos, dentre eles: fotografias, pastas com recortes de reportagens de jornais da época que traziam diferentes notícias sobre o PI, fichas das atividades programadas, para produção de dados para análise do objeto investigado.

Como os PIs da capital, em Campinas esses estabelecimentos recebiam crianças de 3 a 12 anos, oportunizando o convívio de meninas e meninos de várias idades, porém, nesse estudo, o recorte delimitou a faixa etária dos 3 aos 6 anos, a qual era denominada de " 1 a turma", "a turma dos pequenininhos", "turma dos pequenos", entre outras semelhantes, conforme anotações que constam em parte dos documentos pesquisados.

Ressalta-se que, especificamente o conjunto de dez fotografias analisadas, visto que o montante delas apresentava a mistura das faixas etárias, e assim, extrapolava o recorte do objeto de estudo, caracterizou-se por imagens que mostravam as crianças em ambiente externo, ao ar livre, na piscina redonda, na área do teatro de arena e no gramado. 
No entanto, outros documentos serviram de aporte para afirmar que as práticas vivenciadas se davam, geralmente, nesses espaços, visto que, segundo Gonçalves e Leão (1993) as informações trazidas pelo registro fotográfico precisam de contextualização por meio de pesquisas em outras fontes.

Para isso foi analisada uma pasta com recorte de reportagens dos jornais Diário do Povo e Correio Popular (ambos de Campinas) e a Gazeta (de São Paulo), onde selecionei trechos que divulgavam as festas no Parque, e também abordavam o caráter das atividades ali desenvolvidas que, apesar de também trazerem um discurso eugenista, ideologia política vigente na época, que incentivava a prática de atividades físicas para a formação de uma geração forte e sadia, mostravam que as condições ofertadas possibilitavam com que as crianças vivenciassem suas infâncias, ao implementar uma proposta com a inclusão de jogos, cantos, danças, e brinquedos, tais como balanços, escorregadores, etc.

Outras fontes foram as fichas de atividades voltadas para a $1^{\mathrm{a}}$ turma que incluíam desde quadrinhas incentivando às práticas higiênicas, como a descrição de diversos jogos e seus objetivos de desenvolvimento psíquico-físicos. Enfatiza-se que nas fichas também se registrou a possibilidade de mistura das turmas. De acordo com os documentos consultados, as atividades com dança e música também integravam a proposta educacional da instituição.

Analisando a representação da linguagem corporal nos documentos citados nota-se que meninas e meninos realizavam as atividades em espaço ao ar livre, uma vez que a área do PI era privilegiada, possuindo extensa área verde com gramado, além de tanque de vadear, que era uma piscina redonda usada pela $1^{\mathrm{a}}$ turma. Compreende-se que esse tanque, diferentemente da piscina retangular, do tipo olímpica, não tinha o objetivo de que as crianças aprendessem a nadar, mas priorizavam o contato com um dos quatro elementos da natureza, oportunizando brincadeiras na água.

Como aponta Paula (2003), a linguagem corporal vivenciada em espaço externo, fosse através de jogos, brincadeiras, banhos na piscina, apresentações públicas de danças e dramatizações, dá indícios de que meninas e meninos experienciavam situações variadas, ampliando seu repertório de movimentos e construindo culturas infantis.

É possível reconhecer o Parque como um espaço que possibilitava uma educação de corpo inteiro, isto é, que não antecipava a educação do corpo sentado, passivo, controlado da escola formal, promovendo experiências lúdicas e recreativas, contraditoriamente, também se admite o seu caráter reprodutor de um discurso de controle e disciplinarização dos corpos. Maria Walburga dos Santos (2005) explica que: 
Os Parques Infantis são expressão de um movimento interativo entre ideais culturais e educacionais que, mesclados, fazem surgir uma instituição que não é escola nem órgão cultural. Suas atividades estão muito mais identificadas com os ideais da Escola Nova e, como demonstrado, são essas referências que darão a marca pedagógica dos Parques, que carrega a tensão do movimento que propõe: ao mesmo tempo liberdade de expressão pelas atividades de lazer e brincadeiras e adoção de padrões de uma assistência rígida, pré-moldada na difusão de uma cultura higienizante e de caráter padronizador, tanto das questões físicas quanto morais. Em todo o caso, opera-se uma transgressão nos Parques quando se adota o lúdico, a recreação como eixo. Mesmo sob olhares vigilantes das educadoras ou dos ideais traçados em gabinete, é na relação da criança com o brinquedo e com os atrativos do Parque Infantil que se estabelece o processo educativo. (SANTOS, 2005, p.188-189)

Para essa mesma autora, os PIs integravam um sistema de educação mais completo, pois buscavam contemplar amplamente as/os suas/seus frequentadoras/es física e intelectualmente, como também um sistema mais complexo por serem independentes da educação formal, uma vez que: "O sistema educacional do Brasil reproduz estruturalmente características hegemônicas na formação de professores. Tais práticas, aproximadas ao colonial, tendem não somente perpetuar, mas ampliar as desigualdades e exclusões sociais" (dos SANTOS NASCIMENTO; SOUZA, 2020, p.47).

Em seguida, apresento a pesquisa de mestrado que, inspirando-se nas propostas dançantes levadas para os PIs, fez um recorte na obra de MA com o objetivo de identificar os encontros desse intelectual com as manifestações populares brasileiras, com destaque para as danças.

\section{Viva a dança, dança viva!}

"Dance, dance, Zarité, porque escravo que dança é livre... enquanto dança". Eu sempre dancei . ALLENDE, 1942

O escritor modernista MA tem uma vasta produção ao que se refere a estudos sobre as culturas brasileiras. Para realizar a pesquisa de mestrado: "Quem foi que disse que não vivo satisfeito? Eu danço!” Encontros com as danças na obra de Mário de Andrade, tomei como base, principalmente, dois textos: O turista aprendiz e Danças Dramáticas do Brasil (ANDRADE 1976; 1982 respectivamente) com o objetivo de destacar a presença das danças na extensa obra do autor; enfatizar o aspecto lúdico dessas manifestações, o papel que desempenham na construção das identidades das/os brincantes e de seus grupos sociais, além 
de possibilitarem a expressão da linguagem corporal. Registro que essa investigação de mestrado também originou as publicações (PAULA 2013; 2021a).

Foi entre os anos de 1927 a 1929, que Mário de Andrade realizou duas importantes viagens etnográficas, a primeira ocorreu no período de maio a agosto de 1927, delimitando-se a região Amazônica. A segunda foi entre dezembro de 1928 a fevereiro de 1929, quando visitou os seguintes estados da região nordeste: Bahia, Alagoas, Pernambuco, Rio Grande do Norte e a Paraíba.

Ambas empreitadas foram registradas em seu diário de viagem, que mais tarde resultaria na publicação do livro O turista aprendiz (1976). A primeira viagem caracterizou-se mais por um MA explorador, curioso, conforme se lê nos relatos do diário do viajante, atento a tudo e a todos, quase nada lhe passando despercebido.

Assim, a segunda viagem se deu de forma sistematizada, quando o pesquisador se muniu de alguns instrumentos e seguiu para a realização do trabalho de campo. Por muitos anos, MA dedicou-se com afinco aos estudos e pesquisas sobre parte das danças que teve a oportunidade de documentar durante suas viagens às regiões norte e nordeste. Mais tarde, após sua morte, todo este material seria organizado pela sua ex- aluna e colaboradora Oneida Alvarenga, intitulando-se: Danças Dramáticas do Brasil (1982).

Entre os vários estudos do pesquisador sobre as culturas brasileiras, ressalto também a dissertação: $O$ samba rural paulista (ANDRADE, 1937), que foi o trabalho de conclusão feito para o Curso de Etnografia. Neste estudo Andrade abordou a manifestação do samba rural, realizada por negros/as do interior do estado de São Paulo, tendo como base as observações feitas no município de Pirapora do Bom Jesus- SP, em ocasião da festa do santo padroeiro.

Retomo que foi no curso de Pedagogia que conheci mais uma entre as "350 facetas" de Mário de Andrade, que, além de escritor, fotógrafo, pesquisador, etnógrafo, poeta, professor de música, também atuou como educador, isso a partir da leitura de Educação pré-escolar $e$ cultura (FARIA, 2002). O aspecto que me chamou a atenção foi por este intelectual ter propiciado, já naqueles anos, que as crianças frequentadoras dos PIs vivenciassem manifestações das culturas populares brasileiras, incluindo dança, música e dramatização. Conforme afirma a pesquisadora Márcia Gobbi:

A proposta de um projeto pedagógico no qual as artes se encontravam presentes no dia a dia das crianças frequentadoras dos Parques parecia, assim, responder na prática à realização de sua função social. Ela está posta junto a estes meninos e meninas que, com pouca ou mais idade, compõem uma infância cujos direitos à expressão de seu ser, de suas artes, estão resguardadas. Ao observarmos os documentos, as fotos, os desenhos, é 
possível enxergar nos Parques Infantis as artes como um de seus fundamentos. (GOBBI, 2004, p. 140)

Este encontro com o educador que priorizou uma política educacional baseada no binômio educação-cultura, me despertou ainda mais a admiração por conhecer sua obra, todavia pela perspectiva das danças populares, expressões essas que realçam elementos de tradições negras africanas e indígenas, possibilitando reconhecer essas culturas, pois:

A colonialidade do ser cerceou indivíduos em sua liberdade e identidade, rejeitando racionalidade e história não europeias, bem como classificando como maléficas as manifestações culturais e tornando invisível o que é o outro. Julgando como sub-humanidade manifestações epistêmicas e culturais dos povos não-europeus. (dos SANTOS NASCIMENTO; SOUZA, 2020, p.49).

As vivências no grupo de danças populares e os conhecimentos que foram se ampliando ao longo da trajetória acadêmica fizeram com que passasse a considerar o papel de outras linguagens na formação e expressão dos sujeitos. Encontro-me nas palavras de Teodora Alves quando essa afirma que:

Os momentos de encantamento pelas danças populares me levaram a refletir e a perceber que a dança- enquanto manifestação espontânea de vida- denota diversas formas artísticas, sejam através de seus rituais, cortejos, autos espetaculares, nos quais o corpo parece ser ao mesmo tempo sujeito e objeto da própria arte, uma espécie de propulsor dos cerimoniais que integram, entre outras coisas, danças e cantos de nossos povos. É o corpo que dança, canta e encanta os apreciadores com suas nuanças nas festividades existentes em diversas regiões do território brasileiro. (ALVES, 2006, p.18)

Compreendo que conhecer outras práticas educativas-culturais é também uma provocação que MA incita, não avaliando que, necessariamente, essas devam ser transpostas para a instituição escolar, uma vez que não se pretende a escolarização delas, até mesmo por acontecerem em determinados contextos sociais, mas que sejam inspiradoras para transformações do/no pensamento pedagógico, para a reconstrução das pedagogias. Tais ações fazem-se indispensáveis, visto que:

A História do Brasil é acompanhada à sombra do racismo e de tantas outras negações da diversidade. No entanto, são tempos de denúncia e anúncio de potencialidades dos sujeitos com o advento das Leis n. 10639/03 e n. 11645/08 que tornam obrigatórios, respectivamente, o ensino da história e cultura africana/afro-brasileira e indígena na educação brasileira. As políticas de reconhecimento das diferenças favorecem a visibilidade de outras lógicas históricas em oposição à lógica dominante eurocêntrica, além de pôr em debate a descolonização epistêmica.(dos SANTOS NASCIMENTO; SOUZA, 2020, p.51). 
No livro Danças Dramáticas do Brasil (ANDRADE, 1982), MA faz um estudo das origens das manifestações elencadas, e destaca seus elementos africanos, ameríndios e ibéricos. Considerando que:

\begin{abstract}
Nisso o povo brasileiro evolucionou bem sobre as raças que nos originaram e as outras formações nacionais da América. Possuímos um grupo numeroso de bailados, todos eles providos de maior ou menor entrecho dramático, textos músicas e danças próprias. E se me fatiga bastante, pela sua precariedade contemporânea, afirmar que o povo brasileiro é formado das três correntes: portuguesa, africana e ameríndia, sempre é comovente verificar que apenas essas três bases étnicas o povo celebra secularmente em suas danças dramáticas. (ANDRADE, 1982, p.23)
\end{abstract}

Com isso evidencia-se que, historicamente, os grupos, agremiações e comunidades que mantêm diversas manifestações populares têm perpetuado as culturas afro-brasileira e indígena, propiciando aos sujeitos que deles participam o contato com saberes que, muitas vezes, não são acessados em outros contextos sociais, ou ainda, quando o são, podem incorrer de forma limitada, discriminatória e/ou desvalorizada.

Avalio que, os conhecimentos compartilhados por essas organizações sócio-culturais tornam-se referências para suas/seus integrantes por se relacionarem às suas ancestralidades. Também, percebe-se que há saberes que possibilitam o acesso a uma formação que se dá por vias marginais, no caso: músicos e dançarinos (as) populares. Geralmente, nota-se a importância dada para a manutenção das tradições empenhando-se para fazer com que elas não desapareçam, apesar de todas as barreiras que lhe são impostas. Ainda, sobre eles, Teodora Alves aponta que se trata da:

... história em seu estado incorporado, abrindo espaço para que o corpo expresse seus saberes étnico-culturais, de modo que nosso olhar, alicerçado na ideia de habitus, de corporeidade e de conhecimento em rede, nos permita enxergar um corpo não apenas bio-psico-social, mas um corpo como representação do ser no mundo ou do ser do mundo (no sentido dialógico) com suas dimensões, capacidade de expressar-se e de inserir-se em sistemas de relações sociais. (ALVES, 2006, p.63, grifos da autora)

Em 1938, período final de MA na gestão do DCSP, o intelectual coordenou a Projeto Missão de Pesquisas Folclóricas, que resultou na coleta de um grande acervo documental referente às nossas manifestações populares, reunindo desde fotografias, filmes, instrumentos musicais, cadernos de campo, etc. Essa iniciativa aconteceu pelo pesquisador temer o desaparecimento de muitas das nossas culturas, conforme frase que finaliza seu texto introdutório em Danças Dramáticas do Brasil: "Da maneira como as coisas vão indo, a sentença é de morte"iv (ANDRADE, 1982, p. 70). Entendo que tal atuação é um exemplo de 
contraposição ao que o sistema educacional brasileiro tem promovido ao longo de anos, sabendo-se que:

Com a predominância de uma práxis colonial que marca nossos currículos, a história e cultura brasileira não são contadas pelos negros e índios que aqui viveram e vivem, mas sim por uma única cosmovisão válida, aquela pautada a partir da visão europeia. (dos SANTOS NASCIMENTO; SOUZA, 2020, p.47).

Durante a viagem da Missão, o grupo composto por quatro pessoas, acompanhou situações emblemáticas devido à perseguição feita às manifestações de origens africanas, pois eram discriminadas; no entanto, nos relatos do turista, em 1929, Mário já registrara episódios que ilustraram o boicote a essas culturas, evidenciando a falta de apoio governamental, como se percebe no relato a seguir:

Os "Cabocolinhos" saem pelo Carnaval. Saem quando podem porque em nome dum conceito mesmo idiotissimamente nacional de Civilização, as Prefeituras e as Chefaturas de Polícia fazem o impossível pra eles não saírem, cobrando diz-que até duzentos mil-réis a licença. Será possível... os Cabocolinhos saem raramente. Até prá ensaiar dentro de casa, pagam treze paus à Polícia!... (ANDRADE, 1976, pp.320-1)

Passadas décadas de fatos como esse, percebe-se que, mesmo diante das limitações que foram submetidas, essas manifestações sobrevivem, se transformando, se ressignificando, compartilhando saberes, onde se destaca a linguagem corporal, pois como acrescenta Teodora Alves:

A presença do corpo como foco central de muitas manifestações culturais parece ser ainda mais evidente quando direcionamos nosso olhar para expressões da cultura afro-brasileira. Nelas é marcante a presença de um corpo que brinca e se diverte, envolve-se com aspectos místicos, religiosos, étnicos e de resistência. São os Maracatus, as rodas de Capoeira, os Sambas de Roda, os Tambores de Crioula etc. (ALVES, 2006, p.18)

Outro aspecto que julgo relevante no estudo sobre os grupos que cultuam as danças populares é a questão de que, em uma sociedade onde se assiste em muitos contextos a segmentação dos grupos por faixa etária, ocorrer o encontro de gerações. Um exemplo da fragmentação das idades é, sem dúvida, a escola. Entretanto, ao analisar os grupos em questão têm-se outro modelo de organização. As práticas culturais vivenciadas propiciam com que, mesmo havendo a participação de pessoas de várias idades, não se faz necessário segregá-las.

Quando se presencia os ensaios, as apresentações, e até mesmo outras atividades desenvolvidas por essas organizações, observa-se a atuação intergeracional de crianças, jovens e pessoas adultas de muitas idades. MA, como já citado anteriormente, enquanto pesquisador, 
etnógrafo, interessado em aprofundar os conhecimentos sobre nossas culturas populares, teve um olhar bastante atento a vários aspectos relacionados a este campo, sendo que, ao que se refere à atuação das crianças, ele fez interessantes registros, como o transcrito abaixo:

(...) era uma crilada gasosa dançando e cantando na praia. Gente predestinada pra dançar e cantar, isso não tem dúvida. Sem método, sem os ritos coreográficos do coco, o pessoalzinho dançava dos 5 anos aos 13, no mais! Um velhote movia o torneio batendo no bumbo e tirando a solfa. Mas o ganzá era batido por um piazote que não teria 6 anos, coisa admirável. Que precocidade rítmica, puxa! O piá cansou, pediu pra uma pequena fazer a parte dele. Essa teria 8 anos certos mas era uma virtuose no ganzá. Palavra que ainda não vi, mesmo nas nossas habilíssimas orquestrinhas maxixeiras do Rio, quem excedesse a paraibaninha na firmeza, flexibilidade e variedade de mover o ganzá. Custei sair dali. (ANDRADE, 1976, p.308)

Interessante enfatizar que às crianças também se delega funções de protagonismo, pois se tem o objetivo que essas conheçam e mantenham suas culturas, pois mais adiante serão elas as mestras, detentoras de saberes que serão compartilhados com seus pares. Vê-se que a linguagem musical vivenciada por elas propicia que, mesmo sendo crianças de pouca idade, adquiram habilidades como suas/seus parceiras/os mais velhas/os. Por outro lado, a presença das pessoas mais velhas, que em muitos espaços de nossa sociedade são marginalizadas, consideradas como improdutivas, tem nesses contextos papel de destaque, ocupando, geralmente, nessas organizações, grupos, comunidades, a função de mestre/mestra.

Crianças e velhos são sujeitos de vivências individuais e coletivas, que configuram as possibilidades de um patrimônio cultural e social, a um só tempo, particular e universal. São eles, também, que evidenciam a natureza das sociedades modernas altamente estratificadas e classificadoras de coisas, de pessoas e de tudo o mais com que se defronte. Nesse sentido, entra em debate a liberdade de ser criança ou ser velho, sem perder a autonomia e os direitos perante o outro, quase sempre adulto e produtivo... (GUSMÃO, 2003, p. 26-27)

Além dos relatos de Mário, os registros fotográficos realizados em suas viagens etnográficas e pela Missão de Pesquisas Folclóricas são importantes documentos que ilustram esses encontros de gerações. Teodora Alves, em sua pesquisa sobre o Coco de Zambê, também salientou a presença da criança, dialogando com os outros sujeitos, vivenciando as culturas de seu grupo.

Durante nossa permanência na comunidade, observamos, frequentemente, as crianças tentando aprender, imitando os tocadores, os cantadores, e os dançarinos do Zambê. Havia um intenso "diálogo corporal", dando a entender que, para aquelas pessoas, o fato de estarem ali envolvidas com o ritual significa não apenas um momento de apreciação de uma dança, mas uma forma de identificação e de pertencimento àquele grupo étnico. (ALVES, 2006, p.141) 
Ressalto que a aproximação com essas manifestações através da obra de Andrade nos possibilita a construção de novos olhares, o reconhecimento de saberes atrelados às danças populares, podendo relacioná-los aos aspectos educacionais, sociais, culturais, políticos, econômicos, artísticos e étnico-raciais. Com isso, voltar-se para esse campo amplia a perspectiva de territórios para a pesquisa. Particularmente, enquanto professora na educação formal, argumento que esses processos são inspiradores para aqueles/as que buscam referências para repensarem as concepções educacionais.

Passo agora para a última sessão, na qual apresento a pesquisa de doutorado que, inspirando-se nas produções anteriores, teve como uma de suas questões iniciais se haveria em espaços urbanos contextos que também propiciassem o encontro de pessoas de várias idades, e que, possivelmente, as infâncias das crianças negras tivessem protagonismo, com isso o campo escolhido foi uma Escola de Samba.

\section{Na cadência do Samba}

Eu quero morrer numa batucada de bamba Na cadência bonita do samba ALVES, 2009

Nesta terceira sessão segue a exposição da pesquisa denominada: "Pura Alegria, Acredita que acontece!' Infâncias, Identidades negras e Educação na Escola de Samba Camisa Verde e Branco - SP, (PAULA, 2019), a qual foi mais um dos desdobramentos das intersecções entre as temáticas educação, infâncias e culturas populares. A partir deste estudo houve também a publicação de: Infâncias tocadas pelo batuque: A Ala das Crianças de uma Escola de Samba(PAULA, 2021), e Meu maior sonho é ser rei da bateria do Camisa: Vozes das infâncias na Escola de Samba (PAULA, 2021b).

Foi no mestrado (PAULA, 2012) que destaquei o valor implícito às expressões das culturas populares que promovem o encontro de pessoas de diferentes idades, e o protagonismo infantil, pois se percebe esses espaços como também um território para as infâncias.

Na tentativa de aprofundar a compreensão neste campo, a investigação no doutorado trouxe a seguinte interrogação: na contemporaneidade, quais outros espaços que, possivelmente, caracterizam-se por esses aspectos? Incorporei à problemática de estudo a 
categoria étnico-racial para focar, em especial, nas infâncias das crianças negras. Assim, volteime para o estudo que teve como objetivo conhecer as infâncias de meninas e meninos da Ala das Crianças da Escola de Samba Camisa Verde e Branco - SP; trazer as vozes das crianças e problematizar o papel dessa organização na construção das identidades negras e da Educação das crianças da Ala.

Do ponto de vista dos fundamentos metodológicos, busquei atravésda metodologia de pesquisa etnográfica a produção de dados por meio de observação participante, conversas informais registradas em caderno de campo e entrevistas semiestruturadas.

Ao definir o campo de investigação passei a frequentar diversas atividades que acontecem na agremiação no decorrer do ano, sendo assim, nos dois anos da pesquisa de campo participei de atividades como Noite de escolha do Samba-enredo para o Carnaval de 2017; Festa Junina; Festa "Julina"; Missa em comemoração ao aniversário da Escola; Festa de Aniversário da Escola; Bingo das Alas Reunidas; Festa de Aniversário da Velha Guarda; Festa do Chope da Ala Harmonia; Eliminatórias para a escolha do Samba-enredo para o Carnaval 2018; Final da escolha do Samba-enredo Carnaval 2018; Festa de Cosme e Damião; Festa de Confraternização da Ala das Crianças; Festa de Aniversário de crianças componentes da Ala; entrega de fantasias; ensaios na quadra, entre outras.

As festividades ocorridas na quadra da agremiação foram momentos valiosos para observação, uma vez que propiciaram o encontro da comunidade, a presença de componentes e participantes da Escola e a presença de outras Escolas de Samba e do público de modo geral.

A quadra da escola de samba Camisa Verde e Branco é uma referência para seus membros e para os moradores do entorno, e é considerada, pela comunidade, como uma extensão de sua casa ou até uma segunda casa, já que é ali que ela ensaia para o carnaval, se encontra, se reúne, convive, se diverte, samba e faz samba, em um processo de criação e fortalecimento dos vínculos sociais e dos laços afetivos. Ela é utilizada também para pequenas confraternizações - nas quais, cada um, dentro de sua possibilidade, leva alimentos e/ou bebidas - e comemorações de aniversário. Nessas ocasiões, a quadra se caracteriza como um local de partilha, função que contribui para o estreitamento dos laços sociais. (MARQUES, 2016, p.102)

Saliento que, em parte dos eventos e das festas que participei, como Festas Juninas e Julinas, além do Samba, outras sonoridades foram oportunizadas, como: o samba rock, o funk, o axé e a blackmusic, função que fica a cargo do DJ do evento. No entanto, continua sendo o Samba, o gênero musical predominante nessa instituição, fazendo jus ao seu nome: Escola de Samba, o seu elemento identitário. 
Para Cristiana Tramonte (2001), a polaridade modernidade versus tradição seria um tema de debate intenso no mundo do Samba. Em seu livro O Samba conquista passagem, a autora dedica um capítulo para apresentação e discussão de fenômenos que ocorreram a partir da década de 1950 e que provocaram mudanças e transformações nas Escolas de Samba, afirmando que esse processo não deve ser visto com fatalismo nem unidimensionalmente. Segundo ela:

O gigantismo das escolas de samba deve ser compreendido à luz de seu processo anterior, ou seja: o processo vitorioso de conquista de hegemonia das classes populares de origem negra, que não pode ser considerado uma derrota em função das transformações atuais das escolas de samba. (TRAMONTE, 2001, p.81)

Na Escola de Samba pesquisada ressalto que foi principalmente através da música e da dança que identifiquei esse reconhecimento e valorização de nossas heranças, sendo estas relacionadas às nossas ancestralidades. Segundo Sodré (1979), os diversos tipos de Samba são perpassados por um mesmo sistema genealógico e semiótico: a cultura negra. Assim, reconheço o Samba enquanto cultura negra de resistência e existência. Para Hall (2001):

Embora os e as tradições e comunidades negras apareçam e sejam representados na cultura popular sob a forma de deformados, incorporados e inautênticos, continuamos a ver nessas figuras e repertórios, aos quais a cultura popular recorre, as experiências que ficam por trás deles. Em sua expressividade, sua musicalidade, sua oralidade, e na sua atenção rica, profunda e variada à fala; em suas inflexões para o vernacular e o local; em sua rica produção de contranarrativas; e, sobretudo, em seu uso metafórico do vocabulário musical, a cultura negra popular tem permitido trazer à tona, dentro de modos mistos e contraditórios, até da cultura popular mais comercial, os elementos de um discurso que é diferente - outras formas de vida, outras tradições de representação. (HALL, 2001, p.153-154)

Compreende-se que as culturas do Samba existem desde a chegada das/os negras/os africanas/os em terras brasileiras, passando por séculos de repressão e perseguição, mas resistindo perante tantas iniciativas de aniquilamento. Tramonte ao abordar a resistência e a hegemonia cultural do Samba, diz que: "Quando se fala em resistência, referimo-nos ao direito de tocar sua música, de praticar sua religião, enfim de manter sua vida cultural” (TRAMONTE, 2001, p.28). Com o passar dos anos o Samba vai passando de elemento de exclusão social para um instrumento de luta pela inserção e, no caso da Escola de Samba, torna-se a maior expressão do Carnaval brasileiro:

(...) é uma ação cultural que processa e organiza as relações sociais, econômicas e políticas da parcela que aí convive no que convencionamos denominar o "Mundo do Samba". Sua prática desencadeia um processo pedagógico fundamental para as populações que aí vivem, se organizam, 
criam, se relacionam, elaboram arte e realizam cultura. (TRAMONTE, 2001, p. 8)

Percebeu-se que, mesmo diante da afirmação de ser o Carnaval o grande objetivo de todas/os, isto é, como representação da ascensão da agremiação, são os encontros proporcionados pelos piqueniques, ensaios, apresentações e festas vivenciadas/os ao longo do ano que constroem as redes de solidariedade e fortalecem os laços de amizade, afeto e pertencimento. Através deles as crianças e seus familiares experienciam lazer, entretenimento, diferentes linguagens e acessam as culturas do Samba.

Enfatizo que essas vivências proporcionam relações com pessoas de diferentes idades/gerações, o que em nossa sociedade torna-se um diferencial a ser destacado, uma vez que se nota a segmentação das idades no convívio social.

A Escola de Samba do Camisa Verde e Branco vem se mostrando historicamente como um terreiro de expressão das culturas negras, consolidando-se não só como um dos "pedaços" do Samba na cidade de São Paulo, mas também como um terreiro das infâncias de meninas e meninos, possibilitando a construção positiva das suas identidades negras. Esse processo compreende as vivências das linguagens corporais, musicais, visuais e estéticas que são compostos de elementos relacionados à negritude, evocando suas ancestralidades.

\section{Uma obra e suas ressonâncias}

SegundoLuckacs, as obras são revitalizadas pelo tempo, desde que possam responder as ânsias semelhantes às do período em que foram produzidas.

LOPEZ, 1972, p.11

Ao esboçar um diálogo com pesquisas referenciadas, tive por objetivo focalizar o fio condutor que as une. Como exposto inicialmente, através de Faria (2002) fui 'apresentada' ao Mário Educador, intelectual modernista, que implementou a proposta educacional dos PIs de São Paulo (1935-1938), a qual relacionava-se a um projeto político social mais amplo, que tinha como base o binômio educação-cultura. 
Nessa perspectiva elaborei um TCC sobre o segundo PI criado em Campinas, SP, que, conforme Tonolli (1996) seguiu os moldes dos Parques existentes na capital paulista, com isso possibilitando a meninas e meninos das classes populares o acesso a diversas atividades, desde jogos, brincadeiras, vivências artísticas incluindo dança, música e teatro.

Tal estudo provocou inquietações a respeito de como o então gestor público, escritor, poeta, ainda na primeira metade do século XX vislumbrava uma educação que priorizava outras linguagens, e, principalmente, valorizando conhecimentos do campo das culturas populares. Assim, formulei a questão: como foi o encontro de MA com essas manifestações, particularmente com as danças brasileiras?

A partir dessa problemática realizei a pesquisa (PAULA, 2012) que fez o recorte delimitando, em especial, dois textos (ANDRADE, 1976; 1982) do autor que focaram em estudos voltados a essas expressões culturais. Nos referidos trabalhos, frutos de pesquisas etnográficas feitas entre os anos de 1927 e 1929, MA possibilita com que conheçamos um rico repertório de danças existentes em nosso país. O estudo também buscou dialogar com a contemporaneidade por meio de entrevistas com autores/as que também realizaram pesquisas a partir da obra de MA, enfocando a perspectiva cultural, nos possibilitando refletir sobre o papel de grupos, coletivos e comunidades que mantêm diferentes práticas culturais.

Complementando essa trajetória, por sua vez, a pesquisa de doutorado vinculou-se às anteriores por voltar-se para o contexto de uma Escola de Samba, e abordar as infâncias de meninas e meninos negras/os nesse território, avaliandoque esse território também se caracteriza pelo binômio educação-cultura. Um dos principais objetivos foi trazer outras narrativas dessas infâncias, contrapondo as produzidas no âmbito da escola. Dessa maneira, os estudos relacionados procuraram contribuir com a construção de um pensamento pedagógico decolonizador, uma vez que:

O prisma do pensamento decolonial implica em fazer um entrelaçado de teoria-prática por uma ótica de ultrapassagem da colonialidade epistemológica e pedagógica eurocentrada e monocultural, que mantém sua hegemonia nos países que foram submetidos a processos históricos de violência colonial. (dos SANTOS NASCIMENTO; SOUZA, 2020, p.50)

De acordo com Catherine Walsh (apud dos SANTOS NASCIMENTO; SOUZA, 2020), pode-se entender a decolonialidade como a reconstrução radical do ser, do poder e do saber historicamente silenciados.Finalizo corroborando que é necessário pensar a Pedagogia da Infância para além dos espaços formais, reconhecendo as diferentes infâncias, a diversidade cultural brasileira, ampliando nossos olhares para outros contextos sociais, de modo a nos 
inspirarmosà construção de novos tipos de relações, e na proposição de práticas educativas emancipatórias e decoloniais, como nos inspiram os/as autores/as aqui referenciados.

\section{Referências}

ALLENDE, Isabel. A ilha sob o mar. Rio de Janeiro: Bertrand Brasil, 2010.

ALVES, Teodora de Araújo. Herdanças de corpos brincantes: os saberes da corporeidade em danças afro-brasileiras. Natal, RN: Editora da UFRN, 2006.

ANDRADE, Mário de. O samba rural paulista. RAM, ano IV, vol. XLI, p.37-116, nov/1937. . O turista aprendiz. Estabelecimento de texto, introdução e notas de Telê Porto Ancona Lopez. São Paulo, Duas Cidades, Secretaria da Cultura, Ciência e Tecnologia, 1976a.

Danças Dramáticas do Brasil. Edição organizada por Oneyda Alvarenga. 2a Edição. Belo Horizonte: Editora Itatiaia, 1982, 3 vol.

ALVES, Ataulfo. Na cadência do Samba. São Paulo: Gravadora Lua Music, 2009, CD.

BAKHTIN, Mikhail M. A cultura popular na Idade Média e no Renascimento: o contexto de François Rabelais. São Paulo: Hucitec; Brasília: Editora da Universidade de Brasília, 1999. $4^{\text {a }}$ ed.

FARIA, Ana Lúcia Goulart de. Educação Pré-Escolar e Cultura: Para uma Pedagogia da Educação Infantil. $2^{\circ}$ ed. Campinas, SP: Ed. da Unicamp, SP: Cortez, 2002.

GOBBI, Márcia A. Desenhos de outrora, desenhos de agora: os desenhos das crianças pequenas no acervo de Mário de Andrade. Tese de doutorado. Faculdade de Educação, Universidade Estadual de Campinas, Campinas, 2004.

GONÇALVES, Cássia Denise; LEÃO, Flávia C. Os retalhos fotográficos de Geraldo Sesso Jr. BCMU - Campinas, v.5, n.10, p.89-100, dez.1993.

GUSMÃO, Neusa Mendes de. Infância e velhice: desafios da multiculturalidade. IN:

GUSMÃO, Neusa Mendes de (org.). Infância e velhice: pesquisa de ideias.. Campinas, SP: Editora Alínea, 2003, p.15-32.

HALL, Stuart. Que "negro" é esse na cultura popular? Lugar Comum. Rio de Janeiro, n.13-14, p.147159, 2001. Disponível em:

https://edisciplinas.usp.br/pluginfile.php/301609/mod_folder/content/0/Que\%20negro\%20\%C3\%A9\% 20esse $\% 20$ na $\% 20$ cultura $\% 20$ popular\%20negra\% 20-\%20Stuart $\% 20$ Hall.pdf?forcedownload $=1$.

Acesso em: 05 jan. 2022.

LEME, Fernanda de Lucca. Memórias de um Parque Infantil em Campinas: vestígios do pensamento de Mário de Andrade. Dissertação (Mestrado em Educação) - Faculdade de Educação, Universidade Estadual de Campinas, Campinas, SP, 2008. 
MARQUES, Fernanda C. S.; BASTOS, Sênia. O ritual de hospitalidade na escola de samba do Camisa Verde e Branco. Caderno Virtual de Turismo. Rio de Janeiro, v.16 n.1, pp. 95-108, abr. 2016.

PAULA, Roberta Cristina de. Os pequenininhos do parque: a linguagem corporal das crianças pequenas de um parque infantil de Campinas/SP (1942-1952). Trabalho de Conclusão de Curso(TCC),Faculdade de Educação, Universidade Estadual de Campinas, Campinas, SP, 2003.

. "Quem foi que disse que não vivo satisfeito? Eu danço!’. Encontros com as danças na obra de Mário de Andrade. Dissertação (Mestrado em Educação) - Faculdade de Educação, Universidade Estadual de Campinas, Campinas, SP, 2012.

As danças populares na obra de Mário de Andrade. Resgate: Revista Interdisciplinar de Cultura, Campinas, SP, vol. 20, n.2, 2013. DOI: 10.20396/resgate.v20i24.8645744. Disponível em: https://periodicos.sbu.unicamp.br/ojs/index.php/resgate/article/view/8645744. Acesso em: 12 dez. 2021.

"Pura Alegria, Acredita que Acontece!" Infâncias, Identidades Negras e Educação na Escola de Samba Camisa Verde e Branco - SP. Tese (Doutorado em Educação) Faculdade de Educação da Universidade de São Paulo, São Paulo, 2019.

Infâncias tocadas pelo batuque: A Ala das Crianças de uma Escola de Samba. Cadernos de Gênero e Diversidade, 7 (1), p.74-98, 2021. Disponível em: https://periodicos.ufba.br/index.php/cadgendiv/article/view/44116. Acesso em 13 dez. 2021.

"Venham pra roda, vamos começar a brincar": As danças populares e o encontro de gerações. IN: FARIA, Ana Lúcia Goulart de Faria e SILVA, Adriana A. (orgs). Sociologia da Infância em tempos de pandemia e necropolítica. Pedagogias descolonizadoras reinventando novas formas de vida. São Carlos: Pedro \& João Editores, 2021a, p.65-97. Disponível em: http://www.bibliotecadigital.unicamp.br/document/?code=110938\&opt=1. Acesso em: 12 dez. 2021.

PAULA, Roberta Cristina de; PRADO, Patrícia Dias. "Meu maior sonho é ser rei da bateria do Camisa": Vozes das infâncias na Escola de Samba. Revista Inter Ação, 46 (3), p.1492-1507, 2021b. DOI: 10.5216/ia.v46i3.68464. Disponível em: https://www.revistas.ufg.br/interacao/article/view/68464. Acesso em: 05 jan. 2022.

SANTOS NASCIMENTO, Erica Pereira dos; SOUZA, Victoria Guimarães. Formação continuada e a Pedagogia decolonial: o M.A.R. e o Samba. Revista Teias, v.21, n.63, p.46-63, out./dez.2020. Disponível em: https://www.epublicacoes.uerj.br/index.php/revistateias/article/viewFile/53968/36189. Acesso em: 13 dez. 2021.

SANTOS, Maria Walburga dos. Educadoras de Parques Infantis em São Paulo: aspectos de sua formação e prática entre os anos de 1935 e 1955. Dissertação (Mestrado em Educação) Faculdade de Educação, Universidade de São Paulo, SP, 2005.

SOARES, Carmen Lúcia; FRAGA, Alex Branco. Pedagogia dos corpos retos: das morfologias disformes às carnes humanas alinhadas. Pro-posições, FE-Unicamp, v.14, n.2 (41), p.77-90, mai./ago. 2003. 
SODRÉ, Muniz. Samba, o dono do corpo. Rio de Janeiro: Codecri, 1979.

TONOLLI, Maria Fernanda Simões. As origens da educação pré-escolar pública municipal em Campinas: O Parque da Vila Industrial. Trabalho de Conclusão de Curso(TCC),Faculdade de Educação, Universidade Estadual de Campinas, Campinas, SP, 1996.

TRAMONTE, Cristiana. O Samba conquista passagem: as estratégias e a ação educativa das escolas de samba. Petrópolis, RJ: Vozes, 2001.

\footnotetext{
'Versos do Samba Enredo "100\% Camisa Verde e Branco. Carnavalizando Mário de Andrade, o berço do Samba, o poeta e o herói na Paulicéia Desvairada", Carnaval, 2018.

ii Museu de Arte do Rio.

iiiRegistro que no TCC fui orientada pela profa Ana Lúcia Goulart de Faria; no mestrado estive sob orientação da profa. Elisa AngottiKossovitch, sendo ela também membro do GEPEDISC. Realizei o doutorado na Faculdade de Educação da Universidade de São Paulo (FEUSP), sob orientação da profa. Patrícia Dias Prado, que coordena o Corpinfância (Grupo de Estudos Pesquisa e Primeira Infância: Linguagens e Culturas Infantis), grupo que também sou integrante desde 2015.

iv Nesse texto Mário de Andrade critica o conceito de civilização que exclui as manifestações populares, submetendo-as a um olhar preconceituoso, ainda, denuncia a falta de apoio aos grupos e agremiações, por parte do poder público.
} 